DEPARTMENT OF ECONOMICS, MANAGEMENT AND STATISTICS

UNIVERSITY OF MILAN - BICOCCA

DEMS WORKING PAPER SERIES

Limited Asset Market Participation and the Optimal Fiscal and Monetary Policies

Lorenzo Menna, Patrizio Tirelli

No. 284 - October 2014

Dipartimento di Economia, Metodi Quantitativi e Strategie di Impresa Università degli Studi di Milano - Bicocca 


\title{
Limited Asset Market Participation and the Optimal Fiscal and Monetary Policies*
}

\author{
Lorenzo Menna ${ }^{\dagger} \quad$ Patrizio Tirelli ${ }^{\ddagger}$
}

October 15, 2014

\begin{abstract}
A popular argument in favour of price stability is that the inflation-tax burden would disproportionately fall on the poor because wealth is unevenly distributed and portfolio composition of poorer households is skewed towards a larger share of money holdings. We reconsider the issue in a DSGE model characterized by limited participation to the market for interest bearing assets. We show that a combination of higher inflation and lower income taxes reduces inequality. When we calibrate the share of constrained agents to fit the wealth Gini index for the US, the optimal inflation rate is well above $2 \%$. The optimal response to shocks is also affected. Rather than using permanent public debt adjustments to smooth tax distortions, the Ramsey planner front loads tax rates and reduces public debt variations in order to limit the long-run redistributive effects of debt service payments.

Jel codes: E52, E58, J51, E24.

Keywords: trend inflation, monetary and fiscal policy, Ramsey plan, Limited Asset Market Participation.
\end{abstract}

\footnotetext{
*We thank Roberta Cardani, Giovanni Di Bartolomeo, Marco Maffezzoli, Alessandra Pelloni and Emiliano Santoro for useful comments and suggestions. We also thank participants to the XXII Symposium of the Society for Nonlinear Dynamics and Econometrics at the Baruch College in New York and seminar participants at the University of MilanBicocca. The paper is part of the RASTANEWS Project funded by the European Community's 7th Framework Programme (FP7).

${ }^{\dagger}$ University of Milano-Bicocca. Corresponding author: email: lorenzo.menna@unimib.it.

${ }^{\ddagger}$ University of Milano-Bicocca. Patrizio Tirelli gratefully acknowledges financial support from EC project 320278RASTANEWS.
} 


\section{Introduction}

Over the last 30 years income and wealth inequality has been rising in developed economies (see, e.g., Atkinson et al, 2011) and concern has grown for the distributive effects of monetary policies (Galbraith et al, 2007, Coibion et al, 2012). In fact, Central Banks policies are increasingly challenged for their apparently adverse effects on inequality. ${ }^{1}$

A relatively large body of empirical research has pointed out that inflation is particularly harmful for the poor (Easterly et al, 2001) and high inflation and inequality are positively related (Albanesi, 2007). A popular argument in favour of price stability is the asymmetric incidence of the inflation tax when wealth is unevenly distributed and portfolio composition of poorer households is skewed towards a larger share of money holdings, so that the inflation tax burden would disproportionately fall on the poor (Erosa and Ventura, 2002; Boel and Camera, 2009; Schmitt-Grohé and Uribe, 2011). In fact, this is the key justification for endorsing price stability as the primary ECB objective as a contribution to reducing inequality and poverty. ${ }^{2}$ By way of contrast, recent contributions (see, e.g., Ragot, 2014) show that the distribution of money holdings is similar to that of financial wealth and much more unequally distributed than that of consumption, suggesting a stronger impact of the inflation tax on richer households.

In the paper we analyze Ramsey-optimal monetary and fiscal policies when distributive effects of policy actions are accounted for. The issue is important also because the DSGE literature in this field is based on the representative agent assumption and is silent about the redistributive effects of inflation. Its standard prescription is that the optimal steady state inflation rate is near to zero or slightly negative and inflation should be almost completely stabilized along the business cycle (Schmitt-Grohé and Uribe, 2011). The result follows from the interaction of monetary transaction costs, that call for a zero nominal interest rate and a negative growth rate of prices (the Friedman rule), and price adjustment costs, that push the optimal inflation rate to zero. Phelps (1973) conjectured that monetary financing could be used to alleviate the burden of distortionary taxation, when an exogenous amount of public spending has to be financed and lump sum taxation is not available. Schmitt-Grohé and Uribe (2011), in their survey of the literature, argue that the optimality of price stability is robust to the Phelps' effect as well as to other frictions such as downward wage rigidity, hedonic prices, incompleteness of the tax system and the zero lower bound on the nominal interest rate.

We modify the standard DSGE model by introducing Limited Asset Market Participation (LAMP henceforth), in the form of a distinction between holders of interest bearing assets (unconstrained agents) and agents who only own money (constrained agents). ${ }^{3}$ This is a simple and

\footnotetext{
${ }^{1}$ See, e.g., "Inequality. A monetary policy for the 1\%", The Economist, London, Jul 5th 2012, and Belotti and Farley, "Fed policies: Income inequality has been one of the results", San Josè Mercury News, April 4 th 2014.

${ }^{2}$ For instance, in a speech at the International Day for the Eradication of Poverty, Intergroup "Extreme Poverty and Human Rights, Fourth World Committee" event, held on October, 17th 2012 at the European Parliament in Brussels Benoît Cœuré, Member of the Executive Board of the ECB, stated that "...poorer households tend to hold a larger fraction of their financial wealth in cash, implying that both expected and unexpected increases in inflation make them even poorer. In addition, monetary policy shocks and surprise inflation can have an impact on inequality through other sources of income. Income from labour and the unemployment of less-skilled workers tend to be adversely affected to a disproportionate degree during recessions. All in all, recent studies suggest that a higher inflation rate is accompanied by greater income inequality".

${ }^{3}$ Several contributions have already investigated the role of LAMP in DSGE models (Galì et al (2007), Bilbiie and Straub (2013) and Di Bartolomeo et al (2011)), typically assuming that constrained agents do not hold any wealth and consume their current labor income. Here we let constrained agents hold money balances. This is necessary to let the inflation tax be levied also on constrained consumers. An example of this approach is found in Coenen et al (2008).
} 
straightforward way to verify how the optimal rate of inflation should respond to inequality concerns and to the redistributive effects of inflation tax on the poorer part of the population.

Heterogeneity in the access to the market for interest bearing assets is a salient feature of the data. While the majority of US households ${ }^{4}$ (92.5\%) own transaction accounts (including checking, savings, money market deposit accounts and money market mutual funds), only a small minority hold other financial assets, such as stocks, bonds, investment funds and other managed assets (which are held by less than the $20 \%$ of households). The major long term saving vehicle for US households are retirement accounts, held by the $50.4 \%$ of families.

\begin{tabular}{cc} 
& Percentage of Families Holding Asset \\
\hline Transaction Accounts & 92.5 \\
Certificate of Deposits & 12.2 \\
Savings Bonds & 12.0 \\
Bonds & 1.6 \\
Stocks & 15.1 \\
Pooled Investment Funds & 8.7 \\
Retirement Accounts & 50.4 \\
Cash Value Life Insurance & 19.7 \\
Other Managed Assets & 5.7 \\
Other & 8.0 \\
Any Financial Asset & 94.0 \\
\hline Table 1: Data taken from the Federal Reserve Bullettin, June 2012, Vol 98, No 2. 2010 Survey. \\
\hline
\end{tabular}

Excluding such important differences in wealth holdings from macroeconomic models implies that the distributional effects of policies and shocks are also ignored. Our model cannot replicate the observed distribution of individual wealth holdings, but even a simple distinction between holders of interest bearing assets and the rest of the population will be shown to bear important implications for policy design.

Our analysis unfolds in 3 steps. The first one is the identification of the policymaker's incentive to use inflation as a redistributive tool, highlighting the efficiency-equity trade off. To this end we focus on a very simple model where goods are produced by monopolistic firms, individuals inelastically supply labor, public consumption is nil and the subjective discount factor is one, so that the Friedman rule should call for zero inflation. In this model, income inequality is determined by profits entirely earned by assets holders, and we allow the planner to print money to finance lump-sum transfers to non-asset holders. We obtain analytical results showing that inequality in individual wealth holdings unambiguously induces the policymaker to raise inflation, thus highlighting the importance of the redistribution motive in shaping optimal policies.

The second step in our analysis is to allow for an endogenous labor supply, and to assume that the planner can offset monopolistic distortions through inflation-financed production subsidies. We find that it is indeed optimal to levy an inflation tax that increases in the share of households whose wealth is entirely composed of money holdings. This latter result suggests that LAMP should induce the planner to shift the optimal financing mix towards inflation in the more realistic framework where distortionary taxes are needed to finance public expenditures and monopolistic distortions cannot be removed through production subsidies.

\footnotetext{
${ }^{4}$ These statistics refer to the 2010 Survey of Consumer Finances.
} 
To verify this latter conjecture, in the third step of our analysis we compute the Ramsey solution for a medium scale DSGE model. This adds to Schmitt-Grohé and Uribe (2004a) because the identification of the optimal financing mix (inflation and income tax) for a given level of public consumption takes into account the planner's concern for redistribution as a determinant of inflation. We find that LAMP induces the planner to choose a higher inflation rate in order to benefit constrained agents. In contrast with received wisdom, the fundamental reason underlying this result is that expected inflation shifts the fiscal burden towards asset holders. Our result is based on the fact that money holdings are larger for wealthier individuals. Thus shifting the financing mix towards higher inflation and lower direct taxes will raise the overall supply of production factors and mainly benefit non asset holders. A steady state public debt equal to $60 \%$ of GDP and a share of constrained agents that matches the wealth Gini index for the US imply an optimal steady state inflation rate of $2.5 \%$ on a yearly basis.

Finally, we analyze the business cycle implications of LAMP and obtain the optimal responses to a government consumption shock and to a productivity shock. Under the representative agent assumption, Ramsey-optimal fiscal and monetary policies unambiguously recommend very low and stable inflation and minimal income tax volatility over the business cycle (Schmitt-Grohè and Uribe, 2006). Permanent debt adjustment to shocks provides the bulk of macroeconomic stabilization, and is used to obtain tax (and consumption) smoothing. Under LAMP such use of debt is substantially limited by the need to avoid the redistributive effects of permanent debt variations. For the planner it is therefore optimal to let tax rates adjust more strongly to shocks. We also find a modest increase in inflation volatility, which is exploited to drive money holdings (and consumption) of constrained households.

The rest of the paper is organized as follows. Section 2 presents the model. Section 3 describes the competitive equilibrium and defines the Ramsey optimal policy. In section 4 we obtain the steady state results. Section 5 describes the optimal Ramsey dynamics and section 6 concludes.

\section{The model}

We consider an infinite-horizon production economy populated by a continuum of households $i \in$ $[0 ; 1]$. Monopolistic competition and nominal rigidities characterize product and labor markets.

A demand for money is motivated by assuming that money facilitates transactions. Consumption purchases are subject to transaction $\operatorname{costs}^{5}$

$$
s\left(\frac{P_{t, i} c_{t, i}}{M_{t, i}}\right), \quad s^{\prime}\left(\frac{P_{t, i} c_{t, i}}{M_{t, i}}\right)>0 \text { for } \frac{P_{t, i} c_{t, i}}{M_{t, i}}>v_{i}^{*}
$$

where $\frac{P_{t, i} c_{t, i}}{M_{t, i}}$ is the ratio of nominal household's expenditures to money balances and $i$ indexes a generic household. The features of $s\left(\frac{P_{t, i} c_{t, i}}{M_{t, i}}\right)$ are such that a satiation level of money balances $\left(v^{*}>0\right)$ exists where the transaction cost vanishes and, simultaneously, a finite demand for money is associated to a zero nominal interest rate. Following Schmitt-Grohé and Uribe (2004a) the transaction cost is parameterized as follows

$$
s\left(\frac{P_{t} c_{t, i}}{M_{t, i}}\right)=A \frac{P_{t} c_{t, i}}{M_{t, i}}+\frac{B}{\frac{P_{t} c_{t, i}}{M_{t, i}}}-2 \sqrt{A B}
$$

\footnotetext{
${ }^{5}$ See Sims (1994), Schmitt-Grohé and Uribe (2004a), Guerron-Quintana (2009).
} 
The government finances an exogenous stream of expenditures by levying distortionary income taxes and by printing money. Optimal policy is set according to a Ramsey plan.

\subsection{Households}

Households are distributed over the unit interval. A mass $\theta \in[0,1]$ of agents (constrained agents) indexed by $c$, cannot participate in the market for interest bearing assets and does not own firms, while a mass $1-\theta$ of agents (uncontrained agents, henceforth), indexed by $u$ behaves according to the standard model and can buy and sell bonds and own firms. Constrained agents, on the other hand, do hold money balances in order to exploit the transaction technology. All households share the same KPR utility function

$$
U=E_{0} \sum_{t=0}^{\infty} \beta^{t} u\left(c_{t}^{i}, l_{t}^{i}\right) ; u\left(c_{t}^{i}, l_{t}^{i}\right)=\frac{\left(c_{t}^{i}\right)^{1-\sigma_{c}}}{1-\sigma_{c}} e^{\frac{\left(1-\sigma_{c}\right) \eta}{1-\gamma}\left(1-l_{t}^{i}\right)^{1-\gamma}}
$$

.where $\beta \in(0,1)$ is the intertemporal discount rate, $l_{t}^{i}$ denotes a bundle of differentiated labor types $^{6}$ and $c_{t}^{i}$ is consumption. We assume $u\left(c_{t}^{i}, l_{t}^{i}\right)$ to be strictly increasing, concave $\left(\sigma_{c}, \gamma \geq 0\right)$ in consumption and leisure and twice-continuously differentiable. For $\sigma_{c}=1 \mathrm{t}$ collapses to the standard log-utility separable framework. ${ }^{7}$ We are going to consider the latter case throughout the whole paper.

\subsubsection{Unconstrained consumers}

Unconstrained households maximize (3) subject to the flow budget constraint

$$
\begin{gathered}
c_{t}^{u}\left(1+s\left(\frac{P_{t} c_{t}^{u}}{M_{t}^{u}}\right)\right)+k_{t}^{u}+\frac{M_{t}^{u}}{P_{t}}+\frac{B_{t}^{u}}{P_{t}}= \\
\left(1-\tau_{t}\right)\left(w_{t} l_{t}+r_{t}^{k} k_{t-1}\right)+(1-\delta) k_{t-1}^{u}+\tau_{t} \delta k_{t-1}^{u}+\frac{M_{t-1}^{u}}{P_{t}}+\frac{\Pi_{t}^{u}}{P_{t}}+\frac{R_{t-1} B_{t-1}^{u}}{P_{t}}-\frac{\xi_{w}}{2} l_{t}\left(\frac{w_{t} \pi_{t}}{w_{t-1}}-1\right)^{2}+t_{t}
\end{gathered}
$$

and under the constraints

$$
c_{t}^{u} \geq 0, M_{t}^{u} \geq 0, k_{t}^{u} \geq 0
$$

$w_{t}$ is the real wage index; $\tau_{t}$ is the income tax rate; $t_{t}$ denotes real fiscal transfers; $\Pi_{t}$ are firms profits; $R_{t}$ is the gross nominal interest rate, $B_{t}^{u}$ is a nominally riskless bond that pays one unit of currency in period $t+1$. $M_{t}^{u}$ defines nominal money holdings and $\pi_{t}=\frac{P_{t}}{P_{t-1}}$ is the gross inflation rate. $k_{t}^{u}$ denotes the capital stock held by the representative unconstrained household, $r_{t}^{k}$ is the rental rate of capital and $\delta$ is the depreciation rate. Nominal wages are subject to a Rotemberg quadratic adjustment cost: $\xi_{w}$ governs the degree of wage stickiness. Households stand ready to supply any labor effort required by firms at the wage rate set by unions. We assume that the government grants depreciation tax allowances.

Given the functional form of the utility function, the production function and the functional form of the transaction technology, ${ }^{8}$ the non-negativity constraints on consumption, capital and money

\footnotetext{
${ }^{6}$ The characteristics of the labor bundle are specified in section (2.2).

${ }^{7}$ For $\sigma_{c}=1$, the utility function becomes $u\left(c_{t}^{i}, l_{t}^{i}\right)=\ln c_{t}^{i}+\frac{\eta}{1-\gamma}\left(1-l_{t}^{i}\right)^{1-\gamma}$. For $\gamma=1$ preferences are logarithmic also in leisure.

${ }^{8}$ The KPR utility function goes to $-\infty$ as consumption approaches zero. It is also easy to see that the limit of transaction costs for money balances that approach zero is infinite. We consider a Cobb-Douglas production function which implies that zero capital entails zero output and zero consumption.
} 
balances are always non-binding and we can ignore them. Finally, we impose on unconstrained households the standard no-Ponzi game condition on the accumulation of bonds:

$$
\lim _{T \rightarrow \infty} E_{t} \beta^{T-t} B_{T}^{u} \geq 0 .
$$

The first-order conditions of the unconstrained household's maximization problem are: ${ }^{9}$

$$
\begin{gathered}
\lambda_{t}^{u}=\frac{u_{c}\left(c_{t}^{u}, l_{t}\right)}{1+s\left(\frac{c_{t}^{u}}{m_{t}^{u}}\right)+\frac{c_{t}^{u}}{m_{t}^{u}} s^{\prime}\left(\frac{c_{t}^{u}}{m_{t}^{u}}\right)} \\
\lambda_{t}^{u}=\beta E_{t}\left(\frac{\lambda_{t+1}^{u} R_{t}}{\pi_{t+1}}\right) \\
\lambda_{t}^{u}=\beta E_{t}\left\{\lambda_{t+1}^{u}\left[\left(1-\tau_{t+1}\right)\left(r_{t+1}^{k}-\delta\right)+1\right]\right\} \\
1-E_{t}\left[\frac{\beta}{\pi_{t+1}} \frac{\lambda_{t+1}^{u}}{\lambda_{t}^{u}}\right]=s^{\prime}\left(\frac{c_{t}^{u}}{m_{t}^{u}}\right)\left(\frac{c_{t}^{u}}{m_{t}^{u}}\right)^{2}
\end{gathered}
$$

where $m_{t}^{u}=\frac{M_{t}^{u}}{P_{t}}$. As in Schmitt-Grohé and Uribe (2004a) condition (6) states that the transaction cost introduces a wedge between the marginal utility of consumption, $u_{c}\left(c_{t}^{u}, l_{t}^{u}\right)$, and the marginal utility of wealth, $\lambda_{t}^{u}$, that vanishes only if $\frac{c_{t}^{u}}{m_{t}^{u}}=v^{*}$. Equation (7) is a standard Euler condition, while equation (8) is a standard Euler condition for capital. The income tax distorts capital accumulation at the margin, while this is not the case for inflation since the rental rate of capital is not set in advance. Equation (9) implicitly defines the money demand function. Taking into account (7), condition (9) takes the familiar form

$$
1-\frac{1}{R_{t}}=s^{\prime}\left(\frac{c_{t}^{u}}{m_{t}^{u}}\right)\left(\frac{c_{t}^{u}}{m_{t}^{u}}\right)^{2}
$$

where the nominal interest rate defines the opportunity cost of holding money. ${ }^{10}$

\subsubsection{Constrained consumers}

Constrained households maximize (3) subject to the flow budget constraint ${ }^{11}$

$$
c_{t}^{c}\left(1+s\left(\frac{P_{t} c_{t}^{c}}{M_{t}^{c}}\right)\right)+\frac{M_{t}^{c}}{P_{t}}=\left(1-\tau_{t}\right) w_{t} l_{t}+\frac{M_{t-1}^{c}}{P_{t}}-\frac{\xi_{w}}{2} l_{t}\left(\frac{w_{t} \pi_{t}}{w_{t-1}}-1\right)^{2}+t_{t}
$$

The first-order conditions of the constrained household's maximization problem are:

$$
\begin{gathered}
\lambda_{t}^{c}=\frac{u_{c}\left(c_{t}^{c}, l_{t}^{c}\right)}{1+s\left(\frac{c_{t}^{c}}{m_{t}^{c}}\right)+\frac{c_{t}^{c}}{m_{t}^{c}} s^{\prime}\left(\frac{c_{t}^{c}}{m_{t}^{c}}\right)} \\
1-E_{t}\left[\frac{\beta}{\pi_{t+1}} \frac{\lambda_{t+1}^{c}}{\lambda_{t}^{c}}\right]=s^{\prime}\left(\frac{c_{t}^{c}}{m_{t}^{c}}\right)\left(\frac{c_{t}^{c}}{m_{t}^{c}}\right)^{2}
\end{gathered}
$$

\footnotetext{
${ }^{9}$ When solving its optimization problem, the household takes as given goods and bond prices.

${ }^{10}$ Notice that the nominal net interest rate must be non-negative, i.e. $R_{t} \geq 1, \forall t$.

${ }^{11}$ For the reasons discussed above the constraints $c_{t}^{c} \geq 0, M_{t}^{c} \geq 0$ are non binding.
} 
Constrained households' money demand is a negative function of expected inflation and a positive function of the expected increase in the marginal utility of wealth (12). Note that the functional forms in (12) and (9) are identical because both households types define their current money-toconsumption ratio taking into account the discounted payoff from carrying money into the next period. However the implied money-to consumption ratios for the two types are identical only in steady state, when $\frac{\lambda_{t+1}^{u}}{\lambda_{t}^{u}}=\frac{\lambda_{t+1}^{c}}{\lambda_{t}^{c}}=1$ and $R=\frac{\pi}{\beta}$. Outside the steady state the money-toconsumption ratio of unconstrained households can always manage to equalize discounted returns on money and discounted returns on bonds, whereas this possibility is precluded to constrained households. As a result the policy maker may exploit the real interest rate and the level of inflation to steer consumption decisions of the two households groups. ${ }^{12}$

\subsection{Unions}

Following Schmitt-Grohé and Uribe (2006), for each labor type the wage setting decision is delegated to a union and each household stands ready to supply labor on demand. Households work the same amount of time because we assume the two groups are uniformly distributed across unions, and demand for each labour type is uniformly distributed across households, as in Galì et al. (2007). ${ }^{13}$ Each labor union maximises a weighted average of the lifetime utility of its members subject to their budget constraints (equations 4 and 10) and to a downward sloping labor demand function,

$$
l_{t}(j)=l_{t}^{d}\left(\frac{w_{t}(j)}{w_{t}}\right)^{\frac{1}{\rho_{w}-1}}
$$

where $w_{t}(j)$ is the specific wage rate for labor type $\mathrm{j}, l_{t}^{d}$ is a measure of the aggregate labor demand and $\rho_{w}$ is the inverse steady state wage mark-up. The standard Dixit-Stiglitz aggregator allows to consider a representative union. More in detail, the objective function of the representative union is

$$
E_{0} \sum_{t=0}^{\infty} \beta^{t}\left[(1-\theta) u\left(c_{t}^{u}, l_{t}\right)+\theta u\left(c_{t}^{c}, l_{t}\right)\right]
$$

When computing its optimal plan, the union takes into account that for each household total worked hours are $l_{t}=\int_{0}^{1} l_{t}(j) d j$, total pre-tax labor income is $w_{t} l_{t}=\int_{0}^{1} w_{t}(j) l_{t}(j) d j$ and total wage adjustment costs are $\frac{\xi_{w}}{2} l_{t}^{d}\left(\frac{w_{t} \pi_{t}}{w_{t-1}}-1\right)^{2}=\frac{\xi_{w}}{2} l_{t}^{d} \int_{0}^{1}\left(\frac{w_{t}(j) \pi_{t}}{w_{t-1}(j)}-1\right)^{2} d j$. The optimality condition is:

$$
\begin{gathered}
\frac{\left(w_{t} \rho_{w}+\frac{(1-\theta) u_{l}\left(c_{t}^{u}, l_{t}\right)+\theta u_{l}\left(c_{t}^{c}, l_{t}\right)}{\left(1-\tau_{t}\right)\left[(1-\theta) \lambda_{t}^{u}+\theta \lambda_{t}^{c}\right]}\right)}{1-\rho_{w}}+\xi_{w} \frac{w_{t} \pi_{t}}{w_{t-1}}\left(\frac{w_{t} \pi_{t}}{w_{t-1}}-1\right)= \\
\beta E_{t}\left[\frac{l_{t+1}\left[(1-\theta) \lambda_{t+1}^{u}+\theta \lambda_{t+1}^{c}\right]}{l_{t}\left[(1-\theta) \lambda_{t}^{u}+\theta \lambda_{t}^{c}\right]} \xi_{w}\left[\frac{w_{t+1} \pi_{t+1}}{w_{t}}\left(\frac{w_{t+1} \pi_{t+1}}{w_{t}}-1\right)\right]\right]
\end{gathered}
$$

\footnotetext{
${ }^{12}$ This would not be possible in LAMP models where it is assumed that constrained households cannot use money to smooth consumption.

${ }^{13}$ In a separate experiment we consider also a competitive labor market in which unconstrained households and constrained households work a different number of hours. We verified that under a wide range of different calibrations, unconstrained households' worked hours are very small or even zero. Moreover, the difference in worked hours between constrained households and unconstrained households is always large. This is at odds with the data showing that labor income is positively correlated with asset holdings (see Quadrini and Rìos-Rull, 1997). Nevertheless we report results for the competitive labor market case in section (4.3).
} 


\subsection{Labor Packers}

Labor packers buy the differentiated labor types from unions and produce the aggregate labor bundle that they rent to firms. They operate under perfect competition and solve the following problem:

$$
\max w_{t} l_{t}^{d}-\int_{0}^{1} w_{t}(j) l_{t}(j) d j
$$

s.t.

$$
l_{t}=\left(\int_{0}^{1} l_{t}(j)^{\rho_{w}} d j\right)^{\frac{1}{\rho_{w}}}
$$

The optimality conditions are equation (13) and the wage index $w_{t}=\left(\int_{0}^{1} w_{t}(j)^{\frac{\rho_{w}}{\rho_{w}-1}} d j\right)^{\frac{\rho_{w}-1}{\rho_{w}}}$.

\subsection{Intermediate Firms}

The representative intermediate firm produces a differentiated good $z \in(0,1)$ under a standard Cobb-Douglas technology

$$
y_{t}(z)=a_{t} l_{t}(z)^{\alpha} k_{t-1}(z)^{1-\alpha}
$$

and faces a downward sloping demand function,

$$
y_{t}(z)=y_{t}^{d}\left(\frac{P_{t}(z)}{P_{t}}\right)^{\frac{1}{\rho-1}}
$$

where $a_{t}$ is total factor productivity whose logarithm follows an i.i.d. normal stochastic process. We assume a sticky price specification based on a Rotemberg (1982) quadratic cost of nominal price adjustment:

$$
\frac{\xi_{p}}{2} y_{t}^{d}\left(\frac{P_{t}(z)}{P_{t-1}(z)}-1\right)^{2}
$$

where $\xi_{p}>0$ is a measure of price stickiness. In line with Ascari et al (2011), we assume that the re-optimization cost is proportional to output.

In a symmetrical equilibrium the price adjustment rule satisfies:

$$
\frac{\left(\rho-m c_{t}\right)}{1-\rho}+\xi_{p} \pi_{t}\left(\pi_{t}-1\right)=\beta E_{t}\left[\frac{y_{t+1} \lambda_{t+1}^{u}}{y_{t} \lambda_{t}^{u}} \xi_{p}\left[\pi_{t+1}\left(\pi_{t+1}-1\right)\right]\right]
$$

where $m c_{t}$ are the real marginal costs.

Cost minimization implies that the following two equations hold:

$$
\begin{gathered}
w_{t}=a_{t} \alpha m c_{t}\left(\frac{l_{t}}{k_{t-1}}\right)^{\alpha-1} \\
r_{t}^{k}=a_{t}(1-\alpha) m c_{t}\left(\frac{l_{t}}{k_{t-1}}\right)^{\alpha}
\end{gathered}
$$

From (16) it would be straightforward to show that $\frac{1}{\rho}=\mu^{p}$ defines the price markup that obtains under flexible prices. Firm profits are

$$
\frac{\Pi_{t}}{P_{t}}=a_{t} l_{t}^{\alpha} k_{t-1}^{1-\alpha}-w_{t} l_{t}-r_{t}^{k} k_{t-1}-\frac{\xi_{p}}{2} a_{t} l_{t}^{\alpha} k_{t-1}^{1-\alpha}\left(\pi_{t}-1\right)^{2}
$$




\subsection{Final Good Firms}

Final good firms buy differentiated goods from intermediate firms and produce an aggregated good which can be used both for private and public consumption and for investment. They operate under perfect competition and solve the following problem:

$$
\max P_{t} y_{t}^{d}-\int_{0}^{1} P_{t}(z) y_{t}(z) d z
$$

s.t.

$$
y_{t}^{d}=\left(\int_{0}^{1} y_{t}(z)^{\rho} d z\right)^{\frac{1}{\rho}}
$$

The optimality conditions are equation (16) and the price index $P_{t}=\left(\int_{0}^{1} P_{t}(z)^{\frac{\rho}{\rho-1}} d z\right)^{\frac{\rho-1}{\rho}}$.

\subsection{Government budget}

The government supplies an exogenous, stochastic ${ }^{14}$ and unproductive amount of public good $g_{t}$. Government financing is obtained through an income tax, money creation and issuance of oneperiod, nominally risk free bonds. The government flow budget constraint is then given by

$$
R_{t-1} \frac{B_{t-1}}{P_{t}}+g_{t}+t_{t}=\tau_{t}\left(w_{t} l_{t}+r_{t}^{k} k_{t-1}\right)-\tau_{t} \delta k_{t-1}+\frac{M_{t}-M_{t-1}}{P_{t}}+\frac{B_{t}}{P_{t}}
$$

Following Schmitt-Grohé and Uribe (2006), we assume that firms monopoly profits are not taxed. This assumption is typically made in analyses of the optimal inflation rate under distortionary taxation in order to generate a non-trivial policy problem. In fact distortionary taxation does not warrant deviations from the Friedman rule unless factor incomes are suboptimally taxed (see Schmitt-Grohé and Uribe, 2011; and references cited therein). Maintaining this assumption here seems appropriate for two reasons. First, there is a large literature documenting that tax evasion and tax avoidance are related to firms rents. ${ }^{15}$ Second, emphasys on firms ability to escape taxation is particularly relevant in our context, where concern for inequality motivates the Ramsey planner's decisions.

\subsection{Aggregation}

Equations (23)-(28) define aggregate consumption, aggregate hours, aggregate real money balances, bonds, profits, aggregate capital and total output:

$$
\begin{gathered}
c_{t}=(1-\theta) c_{t}^{u}+\theta c_{t}^{c} \\
m_{t}=(1-\theta) m_{t}^{u}+\theta m_{t}^{c} \\
B_{t}^{u}=\frac{B_{t}}{1-\theta}
\end{gathered}
$$

\footnotetext{
${ }^{14}$ We assume that the logarithm of government consumption is normal and i.i.d.

${ }^{15}$ Piketty and Saez (2012) point out that firms can escape taxation by increasing fringe benefits or by allowing managers/entrepreneurs consumption through the use of firms goods or the use of tax heavens. For a broader discussion see Slemrod and Yitzhaki (2002), Saez et al (2012) and Saez (2004).
} 


$$
\begin{gathered}
\Pi_{t}^{u}=\frac{\Pi_{t}}{1-\theta} \\
k_{t}^{u}=\frac{k_{t}}{1-\theta} \\
y_{t}=(1-\theta) c_{t}^{u}\left(1+s\left(\frac{c_{t}^{u}}{m_{t}^{u}}\right)\right)+\theta c_{t}^{c}\left(1+s\left(\frac{c_{t}^{c}}{m_{t}^{c}}\right)\right)+ \\
k_{t}-(1-\delta) k_{t-1}+g_{t}+\frac{\xi_{p}}{2} y_{t}\left(\pi_{t}-1\right)^{2}+\frac{\xi_{w}}{2} l_{t}\left(\frac{w_{t} \pi_{t}}{w_{t-1}}-1\right)^{2}
\end{gathered}
$$

\section{Equilibrium and Ramsey policy}

\subsection{Competitive Equilibrium}

Definition 1 A competitive equilibrium is a set of plans

$$
\left\{c_{t}^{u}, c_{t}^{c}, c_{t}, l_{t}, \lambda_{t}^{u}, \lambda_{t}^{c}, m c_{t}, \pi_{t}, w_{t}, m_{t}^{u}, m_{t}^{c}, m_{t}, y_{t}, b_{t}, R_{t}, k_{t}, r_{t}^{k}, \tau_{t}, t_{t}\right\}_{t=0}^{\infty},
$$

that, given initial values $\left\{m_{-1}^{u}, m_{-1}^{c}, m_{-1}, b_{-1}, k_{-1}\right\}$ and the stochastic processes $\{g\}_{t=0}^{\infty}$ and $\{a\}_{t=0}^{\infty}$, satisfies equations (6),(7),(8),(9),(10),(11),(12),(14),(15),(18),(19),(20),(22),(23),(24),(28), the noPonzi game condition (5) and the non-negativity constraint $R_{t} \geq 1$.

\subsection{Ramsey Optimal Policy}

Definition 2 A Ramsey optimal policy is a competitive equilibrium that attains the maximum of the following additive social welfare function

$$
W=E_{0} \sum_{t=0}^{\infty} \beta^{t}\left((1-\theta) u\left(c_{t}^{u}, l_{t}\right)+\theta u\left(c_{t}^{c}, l_{t}\right)\right)
$$

where the Ramsey plan will satisfy the no Ponzi game condition:

$$
\lim _{T \rightarrow \infty} E_{t} \beta^{T-t} B_{T} \leq 0
$$

The Ramsey program is non-stationary, in the sense that in the initial period the Ramsey planner has an incentive to generate surprise movements in inflation or taxes. We neglect these nonstationary transitory components and concentrate on the time-invariant long run outcome, the Ramsey steady state. This procedure is common in the literature (see for instance Schmitt-Grohé and Uribe, 2004a). ${ }^{16}$

\footnotetext{
${ }^{16}$ Since the analitycal derivation of the first order conditions of the Ramsey plan is cumbersome, we compute them using symbolic Matlab routines. The steady state of the Ramsey program is obtained using the OLS approach suggested in Schmitt-Grohé and Uribe (2011). Dynamics of the Ramsey plan around the steady state are computed using Dynare.
} 


\section{Ramsey Steady State}

The first step in our analysis is the identification of the planner's incentive to use inflation as a redistributive tool, highlighting the efficiency-equity trade off. To this end we greatly simplify the model by imposing several parameter restrictions. In Model A we initially assume that leisure is not valued $(\eta=0)$, prices and wages are flexible $\left(\xi_{p}=\xi_{w}=0\right)$, the discount factor $\beta$ is 1 , labor is the only factor of production $(\alpha=1)$, public expenditure, public debt and the labor tax are nil. Moreover, we set the parameter $A$ in the transaction technology equal to one. Finally, we consider a separable utility function in consumption and leisure, i.e. $\sigma=1$ and $\gamma=1$. The planner's policy instruments are inflation and lump-sum transfers. ${ }^{17}$ This allows to pinpoint the planner's incentive to exploit inflation to finance redistributive policies.

In the second step of our analysis, Model B, we endogeneize the labor supply, allowing for positive values of $\eta$, and we assume that the planner can subsidize production by levying the inflation tax. ${ }^{18}$ The model is already too complex to obtain analytical solutions, and we must rely on numerical methods. To facilitate comparison with model A, we keep the restrictions adopted for $\beta, \xi_{p}, \alpha$ and $\xi_{w}$ and maintain that public expenditure, public debt and the income tax are nil. All the remaining parameters are set as in the full model calibration (see Table 2). This second step will show that efficiency-enhancing policies, such as offsetting monopolisting distortions are implemented with more strength if they also allow to reduce inequality.

Finally we compute the Ramsey solution for the full model, where the planner's problem is the identification of the optimal financing mix for a given level of public expenditures. This latter exercise adds to Schmitt-Grohé and Uribe (2004a) and to Di Bartolomeo et al (2015) because we focus on the planner's concern for redistribution as a determinant of inflation, which remains valid even if redistributive public transfers are not available.

\subsection{Model A: the planner's incentive to use inflation as a redistributive tool}

Definition 3 The social planner allocation in model $A$ is defined as the pair $\left\{c^{u}, c^{c}\right\}$ that maximises $(1-\theta) \ln c^{u}+\theta \ln c^{c}$ subject to the aggregate resource constraint $(1-\theta) c^{u}+\theta c^{c}=l=1 .{ }^{19}$

Proposition 1 For $0<\theta<1$ the optimal pair $\left\{c^{u}, c^{c}\right\}$ is defined by $c^{u}=c^{c}=1$.

Proof. The first order conditions with respect to $c^{u}$ and $c^{c}$ are respectively $\frac{\partial}{\partial c^{u}}=\frac{1-\theta}{c^{u}}-\lambda(1-\theta)=$ 0 and $\frac{\partial}{\partial c^{c}}=\frac{\theta}{c^{c}}-\lambda \theta=0$. Combining the two first order conditions, one obtains $c^{u}=c^{c}$. Given the aggregate resource constraint $(1-\theta) c^{u}+\theta c^{c}=l=1$, it is trivial to see that the solution is $c^{c}=c^{u}=1$. The concavity of the planner objective function makes sure that this is a global maximum.

The equalization of the two levels of consumption under the first best depends on our assumptions about the concavity of the utility function. Indeed it is easy to see that under a linear utility

\footnotetext{
${ }^{17}$ Alternatively, we could have set public transfers to zero and let the planner choose the labor tax optimally, as we do in model B and in the full model. In the context of model A, a labor subsidy (tax) is equivalent to a lump-sum transfer (tax) because the labor supply is perfectly inelastic.

${ }^{18} \mathrm{In}$ model $\mathrm{B}$ and in the full model, we impose that public transfers are equal to zero. Absent this assumption, the Ramsey planner would set them negative to finance production subsidies and government consumption. Imposing zero public transfers is equivalent to constraining the planner not to use lump-sum taxes.

${ }^{19}$ The social planner problem is static. This allows us to consider the steady state solution directly.
} 
function only the sum of the two levels of consumption would be determined, while relative consumption would not be identified. Under a concave utility function the value of a small amount of additional consumption is higher at low levels of income than at high levels of income. The first best allocation cannot be reached until all agents consume at the same level.

Let us now turn to the solution of the Ramsey planner's problem.

Proposition 2 Under the parameter restrictions imposed on Model A, the Ramsey steady state converges to the Golden Rule allocation.

Proof. See Appendix A.

Proposition (2) allows us to compute the Golden Rule of Model A instead of the Ramsey steady state directly. The Golden Rule is obtained by maximising the instantaneous social welfare function subject to the competitive equilibrium conditions after imposing the steady state on the latter. This greatly facilitates derivation of the optimal steady state. In Appendix A we substitute the constraints in the objective function and reduce the Golden Rule problem to a simple unconstrained optimization in one variable.

The problem of the planner is to choose $\pi$ to maximise

$$
W=(1-\theta) \ln c^{u}(\pi)+\theta \ln c^{c}(\pi)
$$

$c^{u}(\pi)$ and $c^{c}(\pi)$ are made explicit in Appendix A.

Proposition 3 For $\theta=0$ the optimal steady state inflation rate is $\pi=1$.

Proof. See Appendix A.

Proposition (3) is the standard Friedman rule result obtained under representative agent models when $\beta=1$. The absence of discounting makes sure that the planner adopts a policy in which no new money is printed and no transfer occurs. Monopolistic competition does not affect the result because labor is supplied inelastically and hours are always equal to one. As a result, the only potential inefficiency comes from the presence of monetary transaction costs. At zero inflation they are nil.

Proposition 4 Consumption inequality is strictly decreasing in inflation.

Proof. In Appendix A, we show that the consumption difference between the two households groups is $c^{u}-c^{c}=\frac{(1-\rho) /(1-\theta)}{1+\frac{B}{\sqrt{B+\frac{\pi-1}{\pi}}}+\sqrt{B+\frac{\pi-1}{\pi}}-2 \sqrt{B}+\frac{(\pi-1) / \pi}{\sqrt{B+\frac{\pi-1}{\pi}}}} \cdot{ }^{20} \quad$ Note that $c^{u}-c^{c}=(1-\rho) /(1-\theta)$ when $\pi=1$. In this case no redistribution occurs and consumption inequality is entirely determined by profits, $(1-\rho) /(1-\theta)$. The term $\frac{B}{\sqrt{B+\frac{\pi-1}{\pi}}}+\sqrt{B+\frac{\pi-1}{\pi}}-2 \sqrt{B}$ represents transaction costs as a share of consumption, while $\frac{(\pi-1) / \pi}{\sqrt{B+\frac{\pi-1}{\pi}}}$ is the inflation tax revenue, used to finance transfers. The derivative of transaction costs with respect to $\pi$ is $\frac{\pi-1}{2 \pi^{3} \sqrt{\left(B-\frac{1}{\pi}+1\right)^{3}}}$ which is unambiguously positive for $\pi>1$. The derivative of the inflation tax revenue is $\frac{\pi+2 B \pi-1}{2 \pi^{3} \sqrt{\left(B-\frac{1}{\pi}+1\right)^{3}}}$, which is positive for $\pi \geq 1$. The term $c^{u}-c^{c}$ is therefore falling in inflation for $\pi>1$.

\footnotetext{
${ }^{20}$ Here we assume $\beta=1$.
} 
A positive inflation rate reduces inequality for two reasons. On the one hand it indirectly taxes consumption out of profits. As a consequence, unconstrained agents, who own firms, contribute more to tax revenues. On the other hand inflation-financed transfers equally benefit the two households groups. ${ }^{21}$

Proposition 5 When $\theta>0 \pi=1$ cannot be a solution to the Ramsey planner's problem.

\section{Proof. See Appendix A.}

Since inequality is strictly decreasing in $\pi$, the planner faces a trade off between efficiency, which would be delivered by eliminating transaction costs, and equity that requires the equalization of consumption of the two agents. Failure of the Friedman rule under agent heterogeneity depends on the fact that (31) is increasing in $\pi$ when $\pi=1$, i.e. the equity motive has a more powerful marginal effect when inflation is nil.

\subsection{Model B: efficiency and redistribution when the labor supply is en- dogenous}

We now endogeneize the labor supply, allowing for $\eta>0$. Under monopolistic competition this implies that the planner is confronted with an efficiency problem. We therefore introduce the possibility of inflation-financed production subsidies, and investigate how the optimum subsidy is affected by agents heterogeneity.

Remark 1 For any value of $\theta$, an endogenous labor supply raises the optimal inflation rate. A higher inflation rate reduces ceteris paribus consumption and leisure inequality.

In Appendix B, we show that the planner's problem can be reduced to a system of two endogenous variables, inflation and the tax rate (which is negative if production is subsidized). Figure 1 provides a graphical exposition. The schedule MW and MW' identify combinations of inflation and subsidy that maximise welfare when parameter $\theta$ takes values 0 and $0.8^{22}$ respectively. Their slopes are positive because an increase in inflation raises transaction costs and lowers the consumption value of labor effort. As a result the planner's incentive to subsidize production (and labor effort) falls. The schedule GG identifies combinations of inflation and production subsidy that are consistent with a balanced budget constraint. its slope is obviously negative.

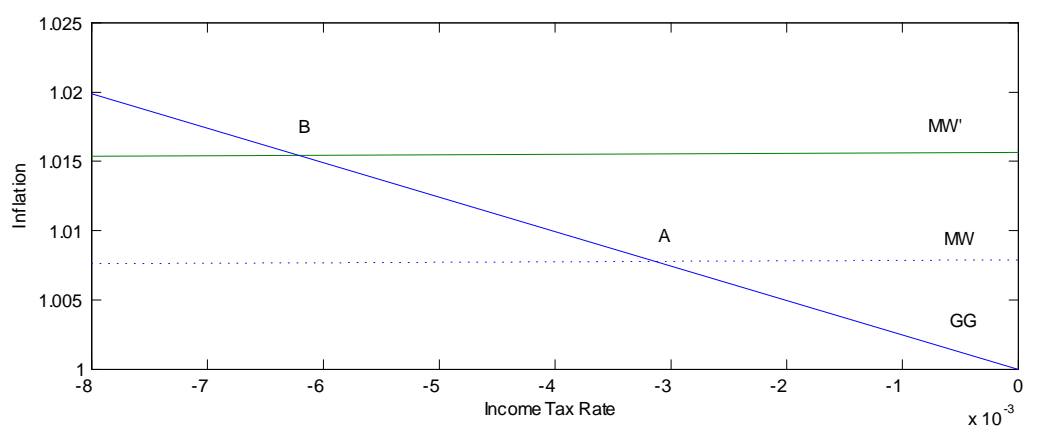

\footnotetext{
${ }^{21}$ The inequality-reducing effect of inflation would obviously be stronger if transfers only accrued to constrained households.

${ }^{22}$ This value fits the wealth Gini index for the US as we are going to explain later on.
} 
Figure 1: GG: Government budget equilibrium. MW: Planner indifference curve under $\theta=0$. MW': Planner indifference curve under $\theta=0.8$.

Note that optimality of the Friedman rule fails even under the representative agent assumption, $\theta=0$. To attain the first best, the planner should set $\tau=\frac{\rho \rho_{w}-1}{\rho \rho_{w}}$ and subsidize labor supply to offset distortions arising from monopolistic competition in the goods and labor markets. But such a policy is costly to obtain as lump-sum taxes are not available. The only way to obtain them is through inflation, which means that to reduce monopolistic distortions, one has to increase consumption transaction costs. The trade-off is resolved at point A, where labor supply is subsidized and the inflation rate is above the Friedman rule level.

Under agent heterogeneity, the trade-off is resolved at higher levels of inflation and of the labor subsidy. Indeed, the planner indifference curve shifts to the left, while the government budget constraint is unaffected. The latter result follows from the fact that, for any given combination of policy tools, $\theta$ does not affect aggregate variables, i.e. total employment and consumption. The planner indifference curve, instead, requires higher levels of inflation, i.e. of redistribution, for any given subsidy, therefore the optimal combination of inflation and subsidy shifts from point A to point B.

The intuition for the result is straightforward. The inflation tax is levied on individual money holdings, so the contribution of unconstrained agents is unambiguously larger. As a matter of fact these agents suffer from a reduction in the consumption value of firms profits. This is only partly compensated for by the increase in labor income, that also accrues to constrained households. As a result consumption inequality unambiguously falls in inflation. ${ }^{23}$

\subsection{The full model}

We now consider the full model. The time unit is a year ${ }^{24}$ and we set the subjective discount rate $\beta$ to 0.96 to be consistent with a steady-state real rate of return of 4 percent per year. As Erosa and Ventura (2002), we set $\alpha$ to $64 \%$ and $\delta$ to $8 \%$. To check the effect of capital accumulation on the optimal inflation rate we also consider the case where labor is the only factor of production $(\alpha=1)$. We set $\rho$ and $\rho_{w}$ such that in the goods and labor markets monopolistic competition implies a gross markup of 1.2, and the annualized Rotemberg price and wage adjustment cost is 4.375 (this implies that firms and unions change their price or wage on average every 9 months, see Schmitt-Grohé and Uribe, 2004a). Following Schmitt-Grohé and Uribe (2004a), the preference parameter $\eta$ is such that under a zero inflation steady state the average household would allocate 20 percent of the time to work; ${ }^{25}$ monetary transaction cost parameters $A$ and $B$ are set at 0.011 and 0.075 respectively, and public consumption is 19\% of GDP. Following Cogan et al (2013) we set steady state public debt at $60 \%$ of GDP. To highlight the effect of steady state public debt on the optimal rate of inflation, we also consider the case where the debt-to-GDP ratio is $80 \%$. We also

\footnotetext{
${ }^{23} \mathrm{~A}$ similar result holds in the model with a competitive labor market and different leisure levels for constrained and unconstrained agents. In that case, a higher inflation rate reduces both consumption and leisure inequality.

${ }^{24}$ In setting the time unit to be a year, we follow the literature. See, e.g., Schmitt-Grohé and Uribe (2004a). Tax rate adjustments require a political process that may take time. As a consequence, it may be difficult to change them at quarterly frequency. We feel one year is a much more realistic time lenght. No fundamental result of the paper depends on this assumption.

${ }^{25}$ This is computed when the public consumption-to-GDP ratio and public debt are nil. With positive public consumption-to-GDP ratios, public debt and inflation rates, the time spent working is slightly lower. Parameter $\eta$ takes on value 2.9, as in Schmitt-Grohé and Uribe (2004a).
} 
experiment with different calibrations of the share of constrained agents $\theta$, but in the benchmark case we set it at 0.8 to match the wealth Gini index for the United States which is around 0.78 (see Quadrini and Rìos-Rull, 1997). ${ }^{26}$ In Appendix C, we report the details of the computation of the model Gini index.

Price and wage stickiness imply an efficiency trade-off between price and wage adjustment costs that disappears at zero inflation, monetary transaction costs vanish at negative inflation. In addition, the introduction of exogenous public consumption expenditures makes sure that the government has to raise some revenues using either distortionary taxation or the inflation tax.

\begin{tabular}{c|ccc|c} 
Parameters & Model A & Model B & Full model & Description \\
\hline$\beta$ & 1 & 1 & 0.96 & Discount Factor \\
$\alpha$ & 1 & 1 & $0.64-1$ & Capital Share \\
$\delta$ & - & - & 0.08 & Depreciation Rate \\
$\sigma$ & 1 & 1 & 1 & Inverse IES \\
$\gamma$ & 1 & 1 & 1 & Exponent on Leisure \\
$\eta$ & 0 & 2.9 & 2.9 & Leisure Weight \\
$A$ & 1 & 0.011 & 0.011 & Trans. Cost Parameter \\
$B$ & $B>0$ & 0.011 & 0.075 & Trans. Cost Parameter \\
$\rho$ & $\rho<1$ & $1 / 1.2$ & $1 / 1.2$ & Inverse Price Mark-up \\
$\rho_{w}$ & - & $1 / 1.2$ & $1 / 1.2$ & Inverse Wage Mark-up \\
$\xi_{p}$ & 0 & 0 & 4.375 & Rotemberg Par. on Prices \\
$\xi_{w}$ & 0 & 0 & 4.375 & Rotember Par. on Wages \\
$\frac{g}{y}$ & 0 & 0 & 0.19 & Public Consumption over GDP \\
$\frac{b}{y}$ & 0 & 0 & $0.6-0.8$ & Public Debt over GDP \\
$\theta$ & $0<\theta<1$ & $0<\theta<0.8$ & $0<\theta<0.8$ & Share of Constrained Agents \\
\hline \multicolumn{4}{c}{ Table 2: Calibration } \\
\hline \multicolumn{4}{c}{}
\end{tabular}

Table 3 summarizes our results. Taking the labor only model as a benchmark, the first column of Table 3 allows to identify the inflationary effects of capital accumulation and rising debt-to-GDP ratio under the representative agent hypothesis. In the model with capital accumulation we obtain an increase in the optimal inflation. Note that in a similar model, Schmitt-Grohé and Uribe (2006) obtain that optimal inflation is $0.5 \%$, slightly below our result. There are some important differences between their model and ours that explain this outcome. Their choice of including transfers in the public expenditure variable unambiguously raises the planner's incentive to inflate, as shown in Di Bartolomeo et al (2015), whereas the cash in advance constraint on firms working capital and the (partial) taxation of profits at the uniform income tax rate work in the opposite direction. Further, their assumption that public debt is only $44 \%$ reduces the optimal inflation rate because debt service payments are equivalent to public transfers and the propensity to inflate rises with the size of transfers. In fact we obtain that optimal inflation is unambiguously higher when public debt is $80 \%$ of GDP.

Limited asset market participation has a non monotonic effect on the optimal inflation rate that falls for $\theta \leq 0.3$ and rises thereafter. ${ }^{27}$ To understand this result we ran a separate experiment

\footnotetext{
${ }^{26}$ The Gini coefficient is computed for a zero inflation steady state model economy and when the public consumption-to-GDP ratio and public debt are nil. It changes only slightly in the presence of positive levels of public consumption and public debt.

${ }^{27}$ In $\theta=0.3$ the optimal inflation rate is around $0.43 \%$
} 
identifying the optimal inflation rate when the Ramsey planner cares only about the welfare of unconstrained agents. A planner who cares only about unconstrained agents' welfare would always set a smaller inflation rate relative to the representative household case. To understand this result bear in mind that a high inflation cum low taxation scenario raises transation costs (thus penalizing the richer households) and raises labor incomes, thus benefitting the poorer households. Note that constrained households, who do not own profits, are particularly penalized by the negative effect of monopolistic competition on labor demand, whereas unconstrained households do not see benefits from increasing their labor effort. Hence, under the Ramsey planner's preferences (eq. 29) the non-monotonic relationship between inflation and $\theta$ obtains because even if a higher inflation rate always benefits constrained agents, at relatively low $\theta$ values such welfare gain is smaller than corresponding welfare loss suffered by unconstrained agents.

By assuming a competitive labor market, we also introduced the possibility that individual labor supplies be different. Note that in this case the flexible nominal wage reduces inflation costs, but the absence of monopolistic distortions also limits the incentive to use inflation as a substitute for income taxes. Under the representative agent assumptions the net effect is a reduction in the optimal inflation rate by about half percentage point. Under LAMP, constrained households raise both worked hours and consumption for any given inflation and tax rate, whereas unconstrained households do just the opposite. By contrast, in a unionized labor market the labor effort is identical and therefore too large (small) for unconstrained (constrained) households. Hence, in a unionized labor market an inflation-financed tax reduction forces unconstrained households to further increase a labor effort which is already suboptimally high at the given wage rate. By contrast, in a competitive labor market each group can optimally adjust its labor supply to the new policy mix. As a result, even at low values of $\theta$ the optimal inflation rate increases relatively to the representative household case. $^{28}$

\begin{tabular}{cccccc} 
& $\theta=0$ & $\theta=0.2$ & $\theta=0.4$ & $\theta=0.6$ & $\theta=0.8$ \\
\hline no capital & $-0.32 \%$ & $-0.33 \%$ & $-0.33 \%$ & $-0.31 \%$ & $-0.19 \%$ \\
full model & $0.73 \%$ & $0.47 \%$ & $0.45 \%$ & $0.8 \%$ & $2.48 \%$ \\
$\frac{b}{y}=0.8$ & $0.94 \%$ & $0.58 \%$ & $0.55 \%$ & $0.95 \%$ & $3.17 \%$ \\
max welfare unconstr. households & $0.73 \%$ & $-0.23 \%$ & $-0.65 \%$ & $-0.89 \%$ & $-1.07 \%$ \\
comp. labor market & $0.33 \%$ & $0.47 \%$ & $0.73 \%$ & $1.51 \%$ & - \\
\hline \multicolumn{6}{c}{ Table 3: Optimal Inflation Rates } \\
\hline
\end{tabular}

\section{$5 \quad$ Ramsey dynamics}

In this section we compute the optimal dynamics for the full model, in the presence of i.i.d. government consumption and productivity shocks. We compare the LAMP model to the representative agent (RA) model. Under LAMP we set $\theta=0.8$. We consider the case with steady state public debt at $60 \%$ of GDP. Figures 2 and 3 report the impulse response functions of the main variables to a $1 \%$ shock.

\footnotetext{
${ }^{28}$ Notice that we do not report results for $\theta=0.8$ under the competitive labor market model. This is due to the fact that when the share of constrained agents is above $63 \%$, the non negativity constraint on worked hours of unconstrained agents is binding. Analysing this corner solution is beyond the scope of the paper.
} 


\subsection{Government consumption shock}

The optimal response of variables to a government spending shock under the representative agent assumption is well known in the literature (see Schmitt-Grohé and Uribe, 2004a) and the addition of capital accumulation does not seem to imply important differences. The trade off between stabilising inflation to avoid price adjustment costs and keeping the nominal interest rate constant to avoid swings in transaction costs is resolved in favor of the former: the Ramsey planner almost completely stabilises inflation. Public debt is used as a cushion to stabilise tax rates and is increased permanently. Output and worked hours increase. Under LAMP debt accumulation still exhibits a unit root, but its long-run adjustment in response to the shock is much smaller than under the representative agent model. This happens because debt accumulation has powerful redistributive effect in favor of unconstrained households. The planner therefore chooses to front load tax adjustment with such strength that consumption of unconstrained households falls even if their gross labor income increases. The different time profile of tax rates implies that output and worked hours are less sensitive to the shock. Finally, the inflation path is not affected by LAMP. Notice that the optimal response to a government consumption shock does not imply a positive response neither of unconstrained agents' consumption, nor of constrained agents consumption. Empirical evidence on the effect of government consumption shocks shows that private consumption responds positively, see e.g. Galì et al (2007). ${ }^{29}$ Galì et al (2007) build a model with LAMP that is able to reproduce the empirical evidence, but their modelization of LAMP is quite different from ours. In their model, constrained agents do not hold money balances and cannot smooth consumption, while in our model they can use money holdings as a store of value. Moreover, our objective is not to fit the empirical evidence, but to outline the optimal response to a government spending shock. We find that it is optimal to let private consumption fall following exogenous shifts in government consumption. This result is compatible with the findings of Horvath (2009), which shows that in a wide calibration range of a standard New Keynesian model augmented for LAMP and consumption-hours non-separability, it is optimal to let private consumption fall in response to government spending shocks.

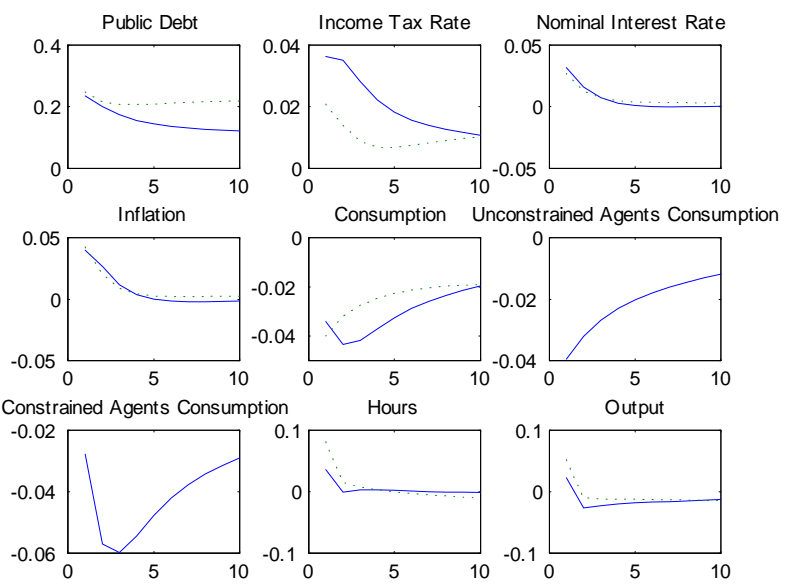

\footnotetext{
${ }^{29}$ Further empirical evidence on the relationship between fiscal policy and LAMP can be found in Coenen and Straub (2005) and Coenen et al (2012).
} 
Figure 2: Response to a government consumption shock. Blue line: heterogenous agents model. Dotted line: representative agent model. - All responses are in percentage deviations from the steady state, apart from the tax rate, the nominal rate and inflation. The latter three variables are 100 times the deviation in levels from the steady state.

\subsection{Productivity shock}

It is well known that under sticky prices, productivity shocks cause a fall of worked hours and a negative output gap. Under the representative agent hypothesis we observe a reduction of the nominal interest rate and of the tax rate, which are meant to remove these effects. In fact output, worked hours and consumption increase, and the surge in total incomes allows to reduce public debt. The lower debt allows to reduce future taxes and to smooth the consumption increase.

Under LAMP the policy mix tilts towards higher taxes and initially lower interest rates. Worked hours and output are less sensitive to the shock, whereas the initial fall in inflation is stronger. The pattern of debt accumulation is quite different. In fact, debt levels remain very stable because the tax smoothing incentive is overwhelmed by the need to limit the redistributive effects of debt service payments.
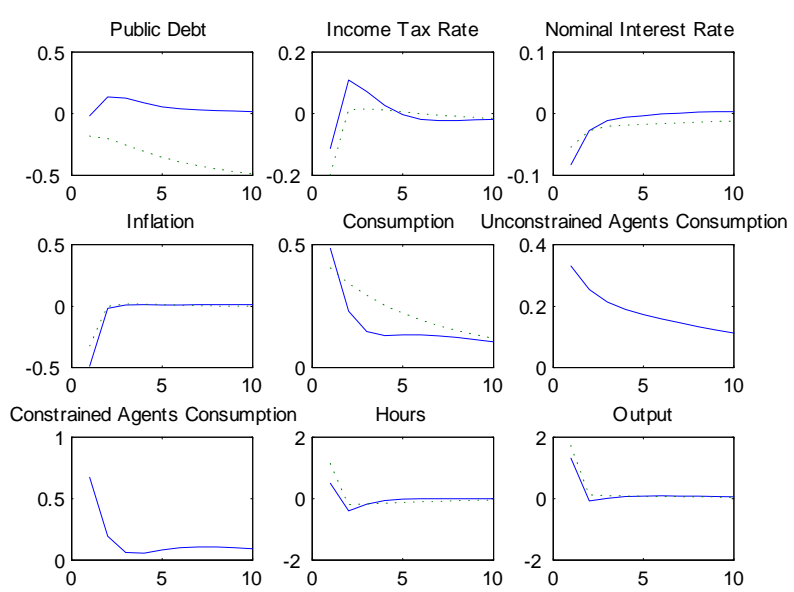

Figure 3: Response to a productivity shock. Blue line: heterogenous agents model. Dotted line: representative agent model. - All responses are in percentage deviations from the steady state, apart from the tax rate, the nominal rate and inflation. The latter three variables are 100 times the deviation in levels from the steady state.

\section{Conclusions}

The main focus of this paper is to study the effect of LAMP on the optimal inflation rate in an otherwise standard DSGE model akin to Schmitt-Grohé and Uribe (2004a). We question the widely held belief that a higher inflation rate would necessarily penalize poorer agents who hold a larger fraction of their wealth in the form of money holdings. Richer households consume more and hold more money, therefore they contribute more to inflation tax revenues that can be used to reduce the burden of direct taxes. As a result worked hours and the relative consumption of 
constrained households increase. In our full model the optimal inflation rate is $2.48 \%$ when the share of constrained households is calibrated to fit the wealth Gini index for the US and the steady state public-debt-to-GDP ratio is $60 \%$. For a $80 \%$ debt ratio optimal inflation is above $3 \%$.

Finally we obtain the optimal response to government consumption and productivity shocks. We find that agent heterogeneity renders optimal to front-load tax adjustment in order to limit the redistributive effects of permanent public debt variations.

\section{References}

Albanesi, S. (2007). "Inflation and inequality." Journal of Monetary Economics, Elsevier, vol. 54(4), pages 1088-1114, May.

Ascari, G., Castelnuovo, E. and Rossi, L. (2011), "Calvo vs. Rotemberg in a trend inflation world: An empirical investigation." Journal of Economic Dynamics and Control, 35: 1852-1867.

Atkinson, A. B., Piketty, T. and Saez, E. (2011). "Top Incomes in the Long Run of History." Journal of Economic Literature, American Economic Association, vol. 49(1), pages 3-71, March.

Bilbiie, F. O. and Straub, R. (2013). "Asset Market Participation, Monetary Policy Rules, and the Great Inflation." The Review of Economics and Statistics, MIT Press, vol. 95(2), pages 377-392, May.

Boel, P., and Camera, G. (2009). "Financial sophistication and the distribution of the welfare cost of inflation." Journal of Monetary Economics, 56(7), 968-978.

Coenen, G. and Straub, R. (2005). "Does Government Spending Crowd in Private Consumption? Theory and Empirical Evidence for the Euro Area." International Finance, Wiley Blackwell, vol. 8(3), pages 435-470, December.

Coenen, G., Straub, R. and Trabandt, M. (2012). "Fiscal Policy and the Great Recession in the Euro Area." American Economic Review American Economic Association, American Economic Association, vol.102(3), pages 71-76, May.

Coenen, G., McAdam, P. and Straub, R. (2008). "Tax reform and labour-market performance in the euro area: A simulation-based analysis using the New Area-Wide Model." Journal of Economic Dynamics and Control, Elsevier, vol. 32(8), pages 2543-2583, August.

Cogan, J. F., Taylor, J. B., Wieland, V. and Wolters, M. H., (2013). "Fiscal consolidation strategy." Journal of Economic Dynamics and Control, Elsevier, vol. 37(2), pages 404-421.

Coibion, O., Gorodnichenko, Y., Kueng, L. and Silvia, J. (2012). "Innocent Bystanders? Monetary Policy and Inequality in the U.S." NBER Working Papers 18170, National Bureau of Economic Research, Inc.

Di Bartolomeo, G., Acocella, N. and Tirelli, P. (2015). "The comeback of inflation as an optimal public finance tool." International Journal of Central Banking, forthcoming.

Di Bartolomeo, G., Rossi, L. and Tancioni, M. (2011). "Monetary policy, rule-of-thumb consumers and external habits: a G7 comparison." Applied Economics, Taylor 65 Francis Journals, Taylor 8 Francis Journals, vol. 43(21), pages 2721-2738. 
Easterly, W. and Fischer, S. (2001). "Inflation and the Poor." Journal of Money, Credit and Banking, Blackwell Publishing, vol. 33(2), pages 160-78, May.

Erosa, A. and Ventura, G. (2002). "On inflation as a regressive consumption tax." Journal of Monetary Economics, Elsevier, vol. 49(4), pages 761-795, May.

Friedman, M. (1969). "The optimum quantity of money." in The optimum Quantity of money and other essays, Chicago, Aldine.

Galbraith, J.K., Giovannoni, O. and Russo, A.J. (2007). "The Fed's Real Reaction Function: Monetary Policy, Inflation, Unemployment, Inequality-and Presidential Politics." Economics Working Paper Archive wp_511, Levy Economics Institute.

Galí, J., López-Salido, J.D. and Vallés, J. (2007). "Understanding the Effects of Government Spending on Consumption." Journal of the European Economic Association, MIT Press, vol. 5(1), pages 227-270, 03.

Guerron-Quintana, P.A. (2009). "Money demand heterogeneity and the great moderation." Journal of Monetary Economics, 56: 255-266.

Horvath, M. (2009). "The effects of government spending shocks on consumption under optimal stabilization." European Economic Review, Elsevier, vol. 53(7), pages 815-829, October.

Phelps, E.S. (1973). "Inflation in the theory of public finance." The Swedish Journal of Economics, 75: $67-82$.

Piketty, T. and Saez, E. (2012). "Optimal Labor Income Taxation." NBER Working Papers 18521, National Bureau of Economic Research, Inc.

Quadrini, V. and Ríos-Rull, J.V. (1997). "Understanding the U.S. distribution of wealth." Quarterly Review, Federal Reserve Bank of Minneapolis, issue Spr, pages 22-36.

Ragot, X. (2014). "The case for a financial approach to money demand." Journal of Monetary Economics, Elsevier, vol. 62(C), pages 94-10\%.

Rotemberg, J.J. (1982). "Sticky prices in the United States." Journal of Political Economy, 90: $1187-1211$

Saez, E. (2004) "Reported Incomes and Marginal Tax Rates, 1960-2000: Evidence and Policy Implications." in James Poterba, ed., Tax Policy and the Economy, 18: 117-174.

Saez, E., Slemrod, J. and Giertz, S. (2012). "The Elasticity of Taxable Income with Respect to Marginal Tax Rates: A Critical Review." Journal of Economic Literature 50(1), 3-50.

Schmitt-Grohé, S. and Uribe, M. (2004a). "Optimal fiscal and monetary policy under sticky prices," Journal of Economic Theory, 114: 198-230.

Schmitt-Grohé, S. and Uribe, M. (2006). "Optimal fiscal and monetary policy in a medium-scale macroeconomic model." in Gertler M. and K. Rogoff (eds.), NBER, Macroeconomics Annual 2005, Cambridge, MIT Press: 383-425. 
Schmitt-Grohé, S. and Uribe, M. (2011). "The optimal rate of inflation." in Friedman B.M. and M. Woodford (eds.), Handbook of Monetary Economics, Elsevier, Amsterdam: 723-828.

Schmitt-Grohé, S. and Uribe, M. (2011). "An OLS approach to computing Ramsey equilibria in medium-scale macroeconomic models." Economics Letters, Volume 115, Issue 1, April 2012, Pages 128-129.

Sims, C.A. (1994). "A simple model for study of the determination of the price level and the interaction of monetary and fiscal policy." Economic Theory, 4: 381-399.

Slemrod, J and Yitzhaki, S. (2002). "Tax Avoidance, Evasion and Administration." In Handbook of Public Economics, 1st edition, Volume 3, eds. Alan Auerbach and Martin Feldstein, 1423-1470. Amsterdam: North-Holland.

\section{Appendix A}

\section{Proof of Proposition 2}

Under the assumptions of flexible prices and wages $\left(\xi_{p}=\xi_{w}=0\right)$, exogenous labor supply $(\eta=0)$ and absence of capital accumulation $(\alpha=1)$ the production side of the model collapses to the trivial equality $w_{t}=\rho$, as can be easily seen from eq. (18) and (19). Since leisure is not valued, households work all the time and $l_{t}=1$. The fact that the upper bound constraint on labor supply is binding makes sure that the labor supply schedule is vertical and monopolistic competition in the labor market is not distortive. Output and the real wage are constants. Profits are constant too and equal to $1-\rho$. In such a setting, the competitive equilibrium of the model collapses to the following system of equations:

$$
\begin{aligned}
& 1-\left[\frac{\beta}{\pi_{t+1}} \frac{\frac{u_{c}\left(c_{t+1}^{c}\right)}{1+s\left(\frac{c_{t+1}^{c}}{m_{t+1}^{c}}\right)+\frac{c_{t+1}^{c}}{m_{t+1}^{c}} s^{\prime}\left(\frac{c_{t+1}^{c}}{m_{t+1}^{c}}\right)}}{\frac{u_{c}\left(c_{t}^{c}\right)}{1+s\left(\frac{c_{t}^{c}}{m_{t}^{c}}\right)+\frac{c_{t}^{c}}{m_{t}^{c}} s^{\prime}\left(\frac{c_{t}^{c}}{m_{t}^{c}}\right)}}\right]=s^{\prime}\left(\frac{c_{t}^{c}}{m_{t}^{c}}\right)\left(\frac{c_{t}^{c}}{m_{t}^{c}}\right)^{2} \\
& 1-\left[\frac{\beta}{\pi_{t+1}} \frac{\frac{u_{u}\left(c_{t+1}^{u}\right)}{1+s\left(\frac{c_{t+1}^{u}}{m_{t+1}^{u}}\right) \frac{c_{t+1}^{u}}{m_{t+1}^{\prime}} s^{\prime}\left(\frac{c_{u+1}^{u}}{m_{t+1}^{u}}\right)}}{\frac{u_{u}\left(c_{t}^{u}\right)}{1+s\left(\frac{c_{u}^{u}}{m_{t}^{u}}\right)+\frac{c_{u}^{u}}{m_{t}^{u}}{ }^{\prime}\left(\frac{c_{u}^{u}}{m_{t}^{u}}\right)}}\right]=s^{\prime}\left(\frac{c_{t}^{u}}{m_{t}^{u}}\right)\left(\frac{c_{t}^{u}}{m_{t}^{u}}\right)^{2} \\
& c_{t}^{u}\left(1+s\left(\frac{c_{t}^{u}}{m_{t}^{u}}\right)\right)+m_{t}^{u}+\frac{B_{t}^{u}}{P_{t}}=\rho+\frac{m_{t-1}^{u}}{\pi_{t}}+\frac{(1-\rho)}{1-\theta}+\frac{R_{t-1} B_{t-1}^{u}}{P_{t}}+t_{t} \\
& c_{t, i}^{c}\left(1+s\left(\frac{c_{t}^{c}}{m_{t}^{c}}\right)\right)+m_{t}^{c}=\rho+\frac{m_{t-1}^{c}}{\pi_{t}}+t_{t} . \\
& R_{t-1} \frac{B_{t-1}}{P_{t}}+g+t_{t}=(1-\theta)\left(m_{t}^{u}-\frac{m_{t-1}^{u}}{\pi_{t}}\right)+\theta\left(m_{t}^{c}-\frac{m_{t-1}^{c}}{\pi_{t}}\right)+\frac{B_{t}}{P_{t}}
\end{aligned}
$$


The Ramsey planner maximises the social welfare function under the constraints given by the competitive equilibrium conditions, before imposing the steady state solution on the latter. Assuming that public debt is nil and public consumption is zero, the Lagrangean is: ${ }^{30}$

$$
\begin{aligned}
& L=\sum_{t=0}^{\infty} \beta^{t}\left((1-\theta) u\left(c_{t}^{u}\right)+\theta u\left(c_{t}^{c}\right)\right)
\end{aligned}
$$

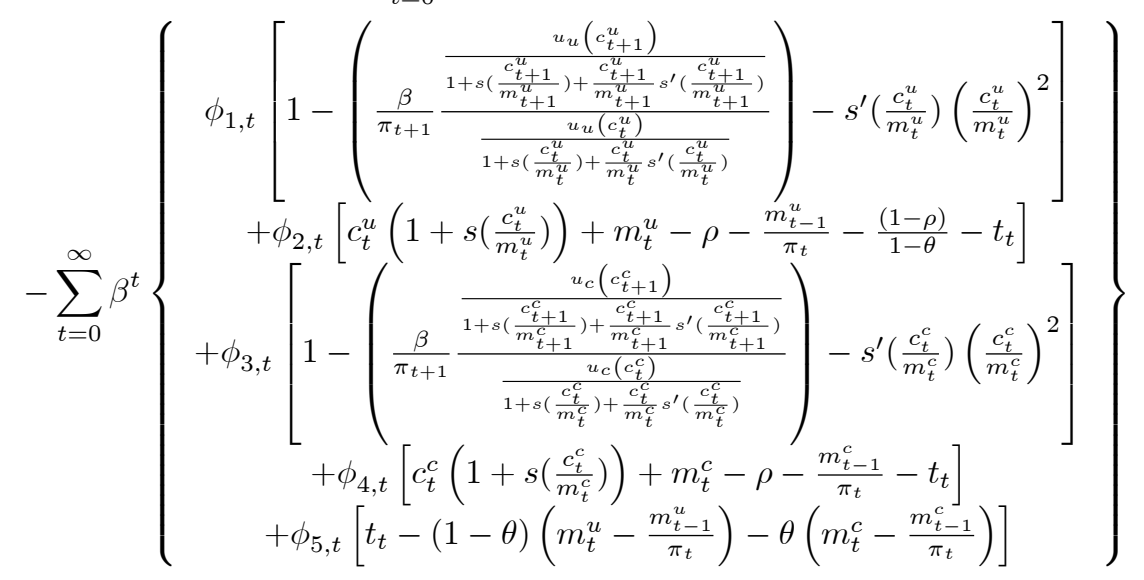

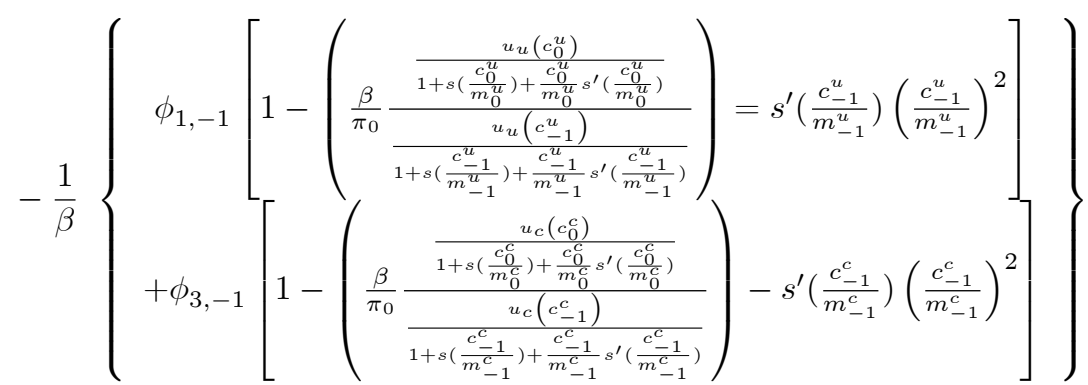

Assuming $\sigma=1, A=1$ and $\beta=1$, computing the first order conditions and imposing the steady state gives rise to the following system of equations:

$$
\begin{gathered}
\frac{\partial L}{\partial c^{u}}=2 \sqrt{B}\left(1-\phi_{2}\right)+\frac{1}{c^{u}}(1-\theta)-\frac{2 c^{u} \phi_{1}}{\left(m^{u}\right)^{2}}-\frac{2 c^{u} \phi_{2}}{m^{u}}=0 \\
\frac{\partial L}{\partial c^{c}}=\frac{\theta}{c^{c}}-\phi_{4}\left(\frac{c^{c}}{m^{c}}-2 \sqrt{B}+c^{c}\left(\frac{1}{m^{c}}-\frac{B m^{c}}{\left(c^{c}\right)^{2}}\right)+\frac{B m^{c}}{c^{c}}+1\right)-\frac{2 \phi_{3} c^{c}}{\left(m^{c}\right)^{2}}=0 \\
\frac{\partial L}{\partial m^{u}}=\frac{2\left(c^{u}\right)^{2} \phi_{1}}{\left(m^{u}\right)^{3}}-\phi_{2}\left(c^{u}\left(\frac{B}{c^{u}}-\frac{c^{u}}{\left(m^{u}\right)^{2}}\right)-\frac{1}{\pi}+1\right)-\phi_{5}(1-\theta)\left(\frac{1}{\pi}-1\right)=0 \\
\frac{\partial L}{\partial m^{c}}=\frac{2\left(c^{c}\right)^{2} \phi_{3}}{\left(m^{c}\right)^{3}}-\phi_{4}\left(c^{c}\left(\frac{B}{c^{c}}-\frac{c^{c}}{\left(m^{c}\right)^{2}}\right)-\frac{1}{\pi}+1\right)-\phi_{5} \theta\left(\frac{1}{\pi}-1\right)=0
\end{gathered}
$$

\footnotetext{
${ }^{30}$ Notice that we include as additional constraints the lagged expectations of the private sector. This allows us to ignore the non-stationary components of the Ramsey plan.
} 


$$
\begin{gathered}
\frac{\partial L}{\partial \pi}=\frac{\phi_{1}+\phi_{3}+m^{u}\left(\phi_{5}(1-\theta)-\phi_{2}\right)+m^{c}\left(\phi_{5} \theta-\phi_{4}\right)}{\pi^{2}}=0 \\
\frac{\partial L}{\partial t}=\left(\phi_{2}+\phi_{4}-\phi_{5}\right)=0
\end{gathered}
$$

The Golden rule equilibrium is obtained by maximising the instantaneous social welfare function under the constraints given by the competitive equilibrium condition after imposing the steady state on the latter. In this case the Lagrangian is:

$$
\left.\begin{array}{c}
L=\left((1-\theta) u\left(c^{u}\right)+\theta u\left(c^{c}\right)\right) \\
\phi_{1}\left[1-\frac{\beta}{\pi}-s^{\prime}\left(\frac{c^{u}}{m^{u}}\right)\left(\frac{c^{u}}{m^{u}}\right)^{2}\right] \\
+\phi_{2}\left[c^{u}\left(1+s\left(\frac{c^{u}}{m^{u}}\right)\right)+m^{u}-\rho-\frac{m^{u}}{\pi}-\frac{(1-\rho)}{1-\theta}-t\right] \\
+\phi_{3}\left[1-\left(\frac{\beta}{\pi}\right)-s^{\prime}\left(\frac{c^{c}}{m^{c}}\right)\left(\frac{c^{c}}{m^{c}}\right)^{2}\right] \\
+\phi_{4}\left[c^{c}\left(1+s\left(\frac{c^{c}}{m^{c}}\right)\right)+m^{c}-\rho-\frac{m^{c}}{\pi}-t\right] \\
+\phi_{5, t}\left[t-(1-\theta)\left(m^{u}-\frac{m^{u}}{\pi}\right)-\theta\left(m^{c}-\frac{m^{c}}{\pi}\right)\right]
\end{array}\right\}
$$

Computing the first order conditions and taking their value for $\beta=1$ gives again equations (37)-(42).

\section{Proof of Proposition 3}

Imposing the steady state condition on equations (32) and (33) and making them explicit, we obtain that $\frac{c^{u}}{m^{u}}=\frac{c^{c}}{m^{c}}=\sqrt{\frac{\pi-\beta}{\pi}+B} \cdot{ }^{31}$ Assuming that debt and public consumption are zero, we can solve equation (36) for $t$ and substitute the value we obtain in equations (34) and (35). Imposing the steady state on the resulting equations and substituting for the consumption to money ratio, we get:

$$
\begin{gathered}
c^{u}=c^{c}+\frac{(1-\rho)}{(1-\theta)\left(1+2 \sqrt{\frac{\pi-1}{\pi}+B}-2 \sqrt{B}\right)} \\
c^{c}=\frac{\rho+c \frac{\frac{\pi-1}{\pi}}{\sqrt{\frac{\pi-1}{\pi}+B}}}{\left(1+2 \sqrt{\frac{\pi-1}{\pi}+B}-2 \sqrt{B}\right)}
\end{gathered}
$$

where $c=(1-\theta) c^{u} \frac{\frac{\pi-1}{\pi}}{\sqrt{\frac{\pi-\beta}{\pi}+B}}+\theta c^{c} \frac{\frac{\pi-1}{\pi}}{\sqrt{\frac{\pi-\beta}{\pi}+B}}, c \frac{\frac{\pi-1}{\pi}}{\sqrt{\frac{\pi-\beta}{\pi}+B}}$ defines the increase in labor income caused by the transfer financed by the inflation tax, $\frac{\pi(1-\rho)}{(1-\theta)\left(1+2 \sqrt{\frac{\pi-1}{\pi}+B}-2 \sqrt{B}\right)}$ defines unconstrained agents' consumption out of profits. It is now straightforward that $c^{u}-c^{c}=$ $\frac{(1-\rho)}{(1-\theta)\left(\left(1+\sqrt{\frac{\pi-\beta}{\pi}+B}+\frac{B}{\sqrt{\frac{\pi-\beta}{\pi}+B}}-2 \sqrt{B}+\frac{\frac{\pi-1}{\pi}}{\sqrt{\frac{\pi-\beta}{\pi}+B}}\right)\right)}$ falls with inflation.

${ }^{31}$ Here we are again assuming that $\mathrm{A}=1$. 
Solving the system given by equations (43) and (44), we can express consumption of the two agents as a function of inflation only. We obtain:

$$
\begin{aligned}
& c^{c}(\pi)= \\
& \rho+(1-\theta) \frac{\rho\left(1+\theta \frac{\frac{\frac{\pi-1}{\pi}}{\sqrt{\frac{\pi-\beta}{\pi}+B}}}{1+\sqrt{\frac{\pi-\beta}{\pi}+B}+\frac{B}{\sqrt{\frac{\pi-1}{\pi}+B}}-2 \sqrt{B}+\frac{\frac{\pi-1}{\pi}}{\sqrt{\frac{\pi-\beta}{\pi}+B}}(1-\theta)}\right)+\frac{(1-\rho)}{1-\theta}}{1+\sqrt{\frac{\pi-\beta}{\pi}+B}+\frac{B}{\sqrt{\frac{\pi-\beta}{\pi}+B}}-2 \sqrt{B}+\theta\left(\frac{\frac{\pi-1}{\pi}}{\sqrt{\frac{\pi-\beta}{\pi}+B}}-\frac{(1-\theta) \frac{\left(\frac{\pi-1}{\pi}\right)^{2}}{\frac{\pi-\beta}{\pi}+B}}{1+\sqrt{\frac{\pi-\beta}{\pi}+B}+\frac{B}{\sqrt{\frac{\pi-\beta}{\pi}+B}}-2 \sqrt{B}+\frac{\frac{\pi-1}{\pi}}{\sqrt{\frac{\pi-\beta}{\pi}+B}}(1-\theta)}\right)} \frac{\frac{\pi-1}{\sqrt{\frac{\pi-\beta}{\pi}+B}}}{{ }^{\frac{\pi}{\pi}}} \\
& 1+\sqrt{\frac{\pi-\beta}{\pi}+B}+\frac{B}{\sqrt{\frac{\pi-\beta}{\pi}+B}}-2 \sqrt{B}+\frac{\frac{\pi-1}{\pi}}{\sqrt{\frac{\pi-\beta}{\pi}+B}}(1-\theta) \\
& c^{u}(\pi)= \\
& \rho\left(1+\theta \frac{\frac{\frac{\pi-1}{\pi}}{\sqrt{\frac{\pi-\beta}{\pi}+B}}}{1+\sqrt{\frac{\pi-\beta}{\pi}+B}+\frac{B}{\sqrt{\frac{\pi-\beta}{\pi}+B}}-2 \sqrt{B}+\frac{\frac{\pi-1}{\pi}}{\sqrt{\frac{\pi-\beta}{\pi}+B}}(1-\theta)}\right)+\frac{(1-\rho)}{1-\theta} \\
& 1+\sqrt{\frac{\pi-\beta}{\pi}+B}+\frac{B}{\sqrt{\frac{\pi-\beta}{\pi}+B}}-2 \sqrt{B}+\theta\left(\frac{\frac{\pi-1}{\pi}}{\sqrt{\frac{\pi-\beta}{\pi}+B}}-\frac{(1-\theta) \frac{\left(\frac{\pi-1}{\pi}\right)^{2}}{\pi}+B}{1+\sqrt{\frac{\pi-\beta}{\pi}+B}+\frac{B}{\sqrt{\frac{\pi-\beta}{\pi}+B}}-2 \sqrt{B}+\frac{\frac{\pi-1}{\pi}}{\sqrt{\frac{\pi-\beta}{\pi}+B}}(1-\theta)}\right)
\end{aligned}
$$

We can now set $\beta=1$ again and rewrite the Golden Rule problem as an unconstrained optimization in just one variable; i.e. inflation. The problem is the following:

$$
\max _{\pi}(1-\theta) \log \left(c^{u}(\pi)\right)+\theta \log \left(c^{c}(\pi)\right)
$$

where $c^{c}(\pi), c^{u}(\pi)$ are defined by eq. (45) and (46) respectively. To prove proposition (3), we assume $\theta=0$. Then we compute the first order condition of problem (47) using symbolic Matlab routines and we obtain the following expression:

$$
\frac{\frac{\pi-1}{\pi} \frac{1}{2 \pi^{2} \sqrt{B+\frac{\pi-1}{\pi}}}}{\left(\frac{\pi-1}{\pi}+B\right)\left(1+\sqrt{\frac{\pi-1}{\pi}+B}+\frac{B}{\sqrt{\frac{\pi-1}{\pi}+B}}-2 \sqrt{B}\right)}=0
$$

It is easy to see that the solution of equation (48) requires $\pi=1 .^{32}$

\section{Proof of Proposition 5}

The first order condition of problem (47), for $\theta>0$, reads as follows:

$$
\frac{c^{c}(\pi)}{c^{u}(\bar{\pi})}=-\frac{\theta}{1-\theta} \frac{c^{c \prime}(\pi)}{c^{u \prime}(\pi)}
$$

\footnotetext{
${ }^{32}$ Equation (48) is never equal to zero for $\pi \neq 1$ and its derivative (the second order condition) is negative in $\pi=1$, hence $\pi=1$ is a global maximum.
} 
To prove that zero inflation cannot be a solution, it is enough to show that $\frac{c^{c}(\pi=1)}{c^{u}(\pi=1)}<1$ and $1=$ $-\frac{\theta}{1-\theta} \frac{c^{c \prime}(\pi=1)}{c^{u \prime}(\pi=1)}$. To show that $\frac{c^{c}(\pi=1)}{c^{u}(\pi=1)}<1$, consider again that $c^{u}-c^{c}=\frac{(1-\rho) /(1-\theta)}{1+\frac{B}{\sqrt{B+\frac{\pi-1}{\pi}}}+\sqrt{B+\frac{\pi-1}{\pi}}-2 \sqrt{B}+\frac{(\pi-1) / \pi}{\sqrt{B+\frac{\pi-1}{\pi}}}}$ $=(1-\rho) /(1-\theta)$ when $\pi=1$. Then note that

$$
(1-\theta) c^{u \prime}(\pi)+\theta c^{c \prime}(\pi)=\frac{-\left(\frac{1-\rho}{1-\theta}+\rho\right)\left(\frac{1}{\pi}-\frac{\pi-1}{\pi^{2}}\right)(\pi-1)}{2 \pi \sqrt{\frac{\pi-1}{\pi}+B}\left(2 B-2 \sqrt{B} \sqrt{\frac{\pi-1}{\pi}+B}+\frac{\pi-1}{\pi}+\sqrt{\frac{\pi-1}{\pi}+B}\right)^{2}}
$$

Expression (50) collapses to zero if $\pi=1$, hence $1=-\frac{\theta}{1-\theta} \frac{c^{c \prime}(\pi=1)}{c^{u \prime}(\pi=1)}$ holds. We now show that (47) is increasing in $\pi$ when $\pi=1$ that is

$$
\frac{\theta}{c^{c}(\pi=1)} c^{c^{\prime}}(\pi=1)+\frac{1-\theta}{c^{u}(\pi=1)} c^{u^{\prime}}(\pi=1)>0 .
$$

Since we showed that $(1-\theta) c^{u \prime}(\pi=1)=-\theta c^{c \prime}(\pi=1)$, we can rewrite (51) as follows

$$
\theta c^{c^{\prime}}(\pi=1)\left(\frac{1}{c^{c}(\pi=1)}-\frac{1}{c^{u}(\pi=1)}\right)>0
$$

which holds because $c^{c}(\pi=1)<c^{u}(\pi=1)$. Since transaction costs are strictly increasing in $\pi$, this is enough to prove that the optimal inflation rate is positive and finite.

\section{Appendix B}

The competitive equilibrium conditions are given by equations (32), (33) and:

$$
\begin{gathered}
c_{t}^{u}\left(1+s\left(\frac{c_{t}^{u}}{m_{t}^{u}}\right)\right)+m_{t}^{u}+\frac{B_{t}^{u}}{P_{t}}=\left(1-\tau_{t}\right) \rho l_{t}+\frac{m_{t-1}^{u}}{\pi_{t}}+\frac{(1-\rho) l_{t}}{1-\theta}+\frac{R_{t-1} B_{t-1}^{u}}{P_{t}} \\
c_{t, i}^{c}\left(1+s\left(\frac{c_{t}^{c}}{m_{t}^{c}}\right)\right)+m_{t}^{c}=\left(1-\tau_{t}\right) \rho l_{t}+\frac{m_{t-1}^{c}}{\pi_{t}} \\
\left(1-\tau_{t}\right) \rho \rho_{w}=\frac{\eta}{1-l_{t}}\left[(1-\theta) c_{t}^{u}\left(1+2 s\left(\frac{c_{t}^{u}}{m_{t}^{u}}\right)-2 \sqrt{B}\right)+\theta c_{t}^{c}\left(1+2 s\left(\frac{c_{t}^{c}}{m_{t}^{c}}\right)-2 \sqrt{B}\right)\right] \\
R_{t-1} \frac{B_{t-1}}{P_{t}}+g=\tau_{t} \rho l_{t}+(1-\theta)\left(m_{t}^{u}-\frac{m_{t-1}^{u}}{\pi_{t}}\right)+\theta\left(m_{t}^{c}-\frac{m_{t-1}^{c}}{\pi_{t}}\right)+\frac{B_{t}}{P_{t}}
\end{gathered}
$$

Equations (32), (33) and (53)-(56) can be combined to obtain the consumption levels of the two agents as a function of inflation and labor taxes, i.e. $c^{i}(\pi, \tau), i=u, c$.

The latter two equation can in turn be used to express also equation (56) as a function of labor taxes and inflation only:

$$
B U D G(\pi, \tau) \equiv \tau \rho l+(1-\theta)\left(m^{u}-\frac{m^{u}}{\pi}\right)+\theta\left(m^{c}-\frac{m^{c}}{\pi}\right)=0
$$


where $l=1-\frac{\eta}{\rho \rho_{w}(1-\tau)}\left[(1-\theta) c_{t}^{u}(\pi, \tau)+\theta c_{t}^{c}(\pi, \tau)\right]\left(1+2 A \sqrt{\frac{\frac{\pi-\beta}{\pi}+B}{A}}-2 \sqrt{A B}\right)$ and $m^{i}=$ $c^{i}(\pi, \tau) \sqrt{\frac{A}{\frac{\pi-\beta}{\pi}+B}}, i=u, c$. After setting $\beta=1,{ }^{33}$ the problem of the planner can be written as:

$$
\begin{gathered}
\max _{\pi, \tau} W(\pi, \tau) \equiv(1-\theta) \log \left(c^{u}(\pi, \tau)\right)+\theta \log \left(c^{c}(\pi, \tau)\right) \\
+\eta \log \left(\frac{\eta}{\rho \rho_{w}(1-\tau)}\left[(1-\theta) c_{t}^{u}(\pi, \tau)+\theta c_{t}^{c}(\pi, \tau)\right]\left(1+2 A \sqrt{\frac{\frac{\pi-1}{\pi}+B}{A}}-2 \sqrt{A B}\right)\right) \\
\text { st } \operatorname{BUDG}(\pi, \tau)=0
\end{gathered}
$$

Using symbolic Matlab routines, we compute the first order conditions of problem (57). We define $\phi$ the Lagrange multiplier on the government budget constraint and obtain:

$$
\begin{gathered}
\frac{\partial W(\pi, \tau)}{\partial \pi}=\phi \frac{\partial B U D G(\pi, \tau)}{\partial \pi} \\
\frac{\partial W(\pi, \tau)}{\partial \tau}=\phi \frac{\partial B U D G(\pi, \tau)}{\partial \tau} \\
B U D G(\pi, \tau)=0
\end{gathered}
$$

Combining equations (59) and (60), we can write

$$
\frac{\partial W(\pi, \tau)}{\partial \pi} / \frac{\partial B U D G(\pi, \tau)}{\partial \pi}=\frac{\partial W(\pi, \tau)}{\partial \tau} / \frac{\partial B U D G(\pi, \tau)}{\partial \tau}
$$

that describes the planner's desired marginal rate of substitution between inflation and the labor tax, which implies an increasing relationship between the two instruments. The intersection between it and equation (61) is the solution to the planner's problem.

\section{Appendix C: Wealth Gini Index}

The steady state wealth of constrained agents is given by their money holdings, $m^{c}$. The steady state wealth of unconstrained agents is given by their money holdings, their holdings of public debt and capital and their holdings of firm shares. Letting the real steady state value of firms be $q$, we can define the wealth of constrained agents $\left(w^{c}\right)$ and unconstrained agents $\left(w^{u}\right)$ as:

$$
\begin{gathered}
w^{c}=m^{c} \\
w^{u}=m^{u}+\frac{b+k+q}{1-\theta}
\end{gathered}
$$

Notice that the value of firms is given by the discounted value of future profits. In the deterministic steady state, future profits are known and constant, hence firms can be priced using the pricing formula of a perpetuity:

$$
q=\frac{1}{R-1} \frac{\Pi}{P}=\frac{\beta}{1-\beta} \frac{\Pi}{P}
$$

\footnotetext{
${ }^{33}$ It can be shown that the equivalence between the Ramsey steady state and the Golden rule equilibrium when $\beta=1$ holds also under model $\mathrm{B}$.
} 
Total private sector wealth is given by $w=m+b+k+q$. Constrained agents, who represent a share $\theta$ of the model population, hold a fraction $\theta \frac{w^{c}}{w}$ of total wealth, while unconstrained agents hold a fraction of wealth equal to $1-\theta \frac{w^{c}}{w}$. Figure 4 reports the Lorenz curve for $\theta=0.8$.

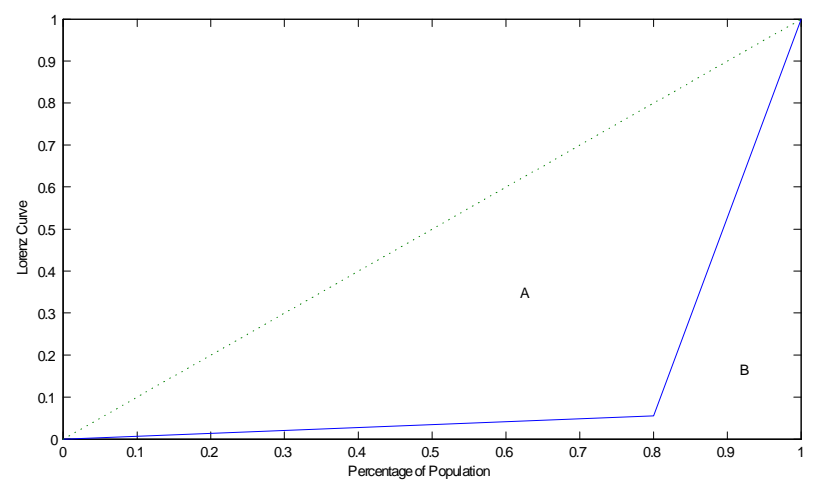

Figure 4: Blue Line: Lorenz curve. Dotted line: line of full equality.

The Gini index is given by 1-2B, where B is the area reported in Figure 4. Area B can be easily computed, using the formulae for the areas of triangles and trapezoids, hence the Gini index is $1-2\left(\frac{\theta^{2} \frac{w^{c}}{w}}{2}+\frac{\left(1+\theta \frac{w^{c}}{w}\right)(1-\theta)}{2}\right)$. 